\title{
Academics as Agentic Superheroes: Female academics' lack of fit with the agentic stereotype of success limits their career advancement
}

\section{Ruth Van Veelen (1) | Belle Derks (i)}

Utrecht University, Utrecht, The Netherlands

\section{Correspondence}

Ruth Van Veelen, Department of Social, Health and Organisational Psychology, Heidelberglaan 1, 3584 CS, Utrecht, The Netherlands.

Email: r.vanveelen@uu.nl

\section{Funding information}

Dutch Network of Women Professors; NWO

VIDI, Grant/Award Number: 016.155.391

\begin{abstract}
Gender gaps in academia persist with women being less likely to attain leadership, earning lower salaries, and receiving less research funding and resources compared to their male peers. The current research demonstrates yet another, more intangible gender gap in academia called lack of fit, whereby compared to male academics, female academics perceive higher misfit between their professional self-concept and the agentic 'superhero' stereotype of the successful academic. The entire population of Dutch academics (i.e., assistant, associate, and full professors from 14 universities) was approached to participate in a nationwide survey. Results from this unique dataset $(N=3978)$ demonstrate that academics perceive agency (e.g., self-confident, self-focused, competitive) as more descriptive of the stereotypical successful academic than communality (e.g., teamoriented, good teacher, collegial). Importantly, early career female academics perceived highest lack of fit with this narrowly-defined agentic occupational stereotype, which was correlated with lower work engagement, professional identification and career efficacy, and higher work exhaustion and exit intentions. Thus, lack of fit seems yet another barrier contributing to pervasive gender gaps in academia.
\end{abstract}


Implications for building more inclusive academic cultures, where not only agentic but also communal academic practice is recognized and rewarded are discussed.

\section{K E Y W O R D S}

career advancement, gender inequality, lack of fit, occupational

stereotypes, women in academia

\section{INTRODUCTION}

Worldwide, women are more educated today than at any point in history. In many Western countries, gender gaps in education are disappearing - at times even to the advantage of women (Centre for Global Development, 2019). However, the improved position of women in education does not translate to the workforce in academia. Gender inequality in academia persists, with female academics facing a number of gender gaps in their careers such as a leadership gap (women are vastly underrepresented at the full professor level; Higher Education Statistics Agency, 2013; LNVH, 2020), a salary gap (female academics earn significantly less; Brower \& James, 2020; LNVH, 2016), a funding gap (female academics' success rates, funding amounts, and PI listings on research grants are significantly lower; Bedi et al., 2012; Witteman et al., 2019), and a resources gap (female academics report significantly less time, facilities, and assistance for research; LNVH, 2019). Over time, these gender gaps feed into the career stagnation and exit of women in academia (Ceci \& Williams, 2011; Shen, 2013).

In the current research, we argue for a fifth, even more subtle gender gap in academia, namely a psychological lack of fit whereby, compared to male academics, female academics perceive themselves to fit less well with the agentic 'superhero' standard of the successful academic. We build from theory on social roles (e.g. Eagly, 1987; Eagly \& Karau, 2002), social identity (e.g., Tajfel \& Turner, 1979), and group stereotypes (e.g., Ellemers, 2018; Fiske et al., 2002) and lack of fit (e.g., Heilman, 1983, 2012), to demonstrate that (1) agentic - rather than communal - traits characterize the occupational stereotype of success in academia, (2) female academics' lack of fit between their professional self-image and the agentic occupational stereotype of success is higher than their male peers, and (3) female academics' higher lack of fit imposes a barrier to their work and career outcomes. We investigate this in a unique dataset of almost 4000 academics sampled from the entire Dutch population of assistant/associate/full professors at all 14 universities in the Netherlands. ${ }^{1}$

This paper advances literature on lack of fit in several ways. While prior studies examined lack of fit mainly subjectively by directly asking women about their experienced fit with their profession (e.g., 'I see myself as quite different from [professional group]'; e.g., Morgenroth et al., 2021; Peters et al., 2012, 2013) we take a novel, socio-cognitive, and trait-based approach that allows for a more objective and indirect study of lack fit (Judge \& Cable, 1997). Specifically, we conceive of the self and an occupational prototype as two separate entities, and establish lack of fit based on the cognitive discrepancy between trait-ratings measured for the self and the prototype on stereotype-relevant domains (e.g., Otten \& Epstude, 2006; Smith \& Henry, 1996). Different from more explicit, subjective measures of lack of fit, cognitive lack of fit is not a motivated response and can be assessed even when people are not aware of subjectively experiencing a lack of fit, or are

\footnotetext{
${ }^{1}$ The data reported in this manuscript was part of a larger project about working in academia. A subsample was previously published in 'Economisch Statistische Berichten', a non-scientific Dutch trade magazine for economic practitioners (Derks et al., 2018) and served a different purpose: namely to demonstrate that the occupational stereotype in Economics \& Business was highly agentic compared to three other fields $(N=2.256)$ and that lack of fit was more prevalent. Note, that this publication did not investigate gendered consequences of lack of fit for work and career outcomes at different ranks, nor did it investigate the entire sample. This manuscript includes the full sample $(N=3978$; eight disciplines), explicitly focuses on gender differences in lack of fit in relation to work and career outcomes, and includes multiple covariates to control for a priori gender differences in Academic discipline (Simpson's Paradox), Academic age (linear and quadratic), Contract Size and Contract Type (Table S4).
} 
unwilling to report this. Moreover, a cognitive approach to assessing lack of fit informs us about the specific content of the stereotype that people see, the way they see their professional self and how the discrepancy between these two components forms a cognitive basis for (lack of) self-concept fit. Furthermore, there is a clear theoretical and empirical evidence to show that people with high self-to-group cognitive fit are more likely to identify highly with a [professional] group and experience high collective self-esteem (see Integrated Model to Social Identification; Van Veelen et al., 2016). To our knowledge, we are the first to apply this socio-cognitive approach to lack of fit to advance psychological insight in gendered careers in academia.

\section{Masculine culture and gender stereotypes in academia}

Universities increasingly endorse the importance of having a (gender) diverse workforce, and numerous actions are taken to promote women's representation and career advancement in academia (League of European Research Universities, 2019). Yet, closing existing gender gaps is easier said than done. Across academic disciplines, gender discrimination, (sexual) harassment, and hostility towards female faculty is still prevalent and severely damaging women's well-being and academic careers (Crabtree \& Shiel, 2019; Naezer et al., 2019; National Academy of Sciences, 2021). Female faculty are socially excluded or marginalized, for example from powerful social networks, from departmental decision-making bodies, and from support systems that stimulate career advancement (Casad et al., 2021; Collins \& Steffen-Fluhr, 2019). Women in academia are also disproportionately burdened with time-consuming non-promotable tasks, for example higher teaching loads (Carrigan et al., 2011), more special favour requests from students (El-Alayli et al., 2018), and more service activities (Bagilhole, 2017; Belle et al., 2014). Finally, work-life balance policies in academia have been coined as highly 'family-unfriendly', with women - more than men - facing career penalties when having children (Cech \& Blair-Loy, 2019; Kachchaf et al., 2015).

The often implicit yet pervasive gender stereotype that women 'do not have what it takes' and lack the agentic qualities (e.g., being independent and competitive) associated with scientific ${ }^{2}$ ability forms a crucial mechanism to explain persistent gender inequalities in academia (e.g., Carli et al., 2016; Cheryan et al., 2015; Moss-Racusin et al., 2012). Children, parents, and teachers alike associate a prototypical scientist more easily with a man than with a woman (Bian et al., 2018; Storage et al., 2020). For example, asking 14-year-old children to 'draw a scientist' results in $75 \%$ of all drawings being portrayed as middle-aged White men (Miller et al., 2018). The same gendered associations hold for adults too (Miller et al., 2015). A large-scale study among 66 nations demonstrates that the more science ability is implicitly associated with men, the more pervasive the underrepresentation of women in academia within that nation. As a case in point, the Netherlands ranked 2nd place on this implicit science women stereotype, corresponding to a markedly high underrepresentation of women in science (Miller et al., 2015). Finally, academics themselves hold gendered notions about their profession too. Scientific ability is often seen as an innate, raw talent, a brilliance held more strongly by men than by women. The stronger academics endorse this gender stereotype, the stronger women's underrepresentation within that academic discipline (Leslie et al., 2015).

Despite mounting evidence disproving gender stereotypes about women's lower ability in science (Eagly et al., 2020; Ellemers, 2018; Hyde, 2014), academia is still viewed as a 'men's world', where men pre-dominate and in which men are believed to be more competent than women. Academics are thus likely to hold a highly 'masculine' stereotypical image of what it takes to be a successful professional in academia. Qualitative research shows that in constructing a prototypical image of 'academic excellence', leaders in academia (i.e., faculty deans) consider being self-confident, self-focused, competitive, and performance-oriented to be more important for success than being a team player, a nice colleague, a good teacher, and a collaborator (Bleijenbergh et al., 2013; Van den Brink \& Benschop, 2012). And these ingredients of academic success fit with the current reward and promotion culture in academia, which is still largely based on individual performance-indicators such as the number and impact of

\footnotetext{
${ }^{2}$ The term science is not synonymous to the term academia. Science only includes the exact, natural, and social sciences, while academia includes all academic disciplines (including e.g., humanities, law). While the terms should not be conflated, the work on science stereotypes is relevant to our research on academia.
} 
first-authored publications, $\mathrm{H}$-indexes and acquisition of highly competitive personal research funds or awards, rather than teaching, mentoring, team science, and interdisciplinary collaboration (Ellemers, 2021; McKiernan et al., 2019).

Building on social role theory (Eagly, 1987; Eagly et al., 2000) and stereotype-content model (Fiske et al., 2002), we distinguish between two universal, yet gendered dimensions to construct an occupational stereotype of the successful academic professional, namely agency (e.g., achievement-oriented, competitive, self-focused, self-confident), which is typically associated with men or masculinity, and communality (e.g., relationship-oriented, kind, helpful, cooperative, concerned for others) which is typically associated with women and femininity (Cejka \& Eagly, 1999; Eagly \& Steffen, 1984; Koenig \& Eagly, 2014). Given that academia is stereotyped as male or masculine, we expect academics to consider agentic traits more descriptive of the occupational stereotype of a successful academic relative to communal traits (Hypothesis 1).

\section{Academics' professional self-descriptions}

To the extent that the masculine culture in academia is likely to define career success in terms of an agentic rather than communal occupational stereotype, this should also inform our understanding of how this image of success is reflected in female and male academics' professional self-concept. Gender roles and stereotypes that portray women as communal and men as agentic are not only used to describe others, but they can also be internalized and become a part of a person's self-concept (e.g., Wood \& Eagly, 2015). In early childhood, we learn about gender stereotypes and they inform us on how we should behave in accordance with our gender identity as boy or girl. These socializations generally lead men and women to self-describe in stereotype-congruent ways in their adult life (Spence \& Buckner, 2000). In work contexts such as in academia, however, contemporary gender stereotypes that prescribe women to be communal are tied up with agency-based expectations that set the normative standard for professional success. This complicates women's professional self-descriptions, especially with regards to their self-views on agency (Hentschel et al., 2019).

In masculine work contexts, women must walk a tightrope (Williams \& Dempsey, 2014), with on the one hand a gender identity that prescribes communality (i.e., warm, social), and on the other hand a professional identity that prescribes agency (i.e., competitive, self-focused). As a way of attaining career success while coping with a low-status gender identity at work, research on the Queen Bee phenomenon (e.g., Derks et al., 2016; Ellemers et al., 2004; Faniko et al., 2021) demonstrates that female academics at higher academic ranks tend to describe themselves more strongly in agentic terms than those at lower ranks. Similar patterns were found among male faculty too. Thus, we expect both male and female academics to rate their professional self as more agentic the higher their academic rank (i.e., assistant, associate, full professor; Hypothesis 2).

In addition, we explore (but have no a priori expectations on) whether communal self-descriptions are different depending on gender and rank. The aforementioned work on the Queen Bee phenomenon did not find that female academics' tendency to emphasize agentic traits coincided with lower communal self-descriptions. Nevertheless, we will explore female academics' communal self-descriptions depending on rank, given the various ways in which self-group distancing manifests across empirical studies (Van Veelen et al., 2020).

\section{Not agentic enough? Lack of fit with the occupational stereotype in academia}

Heilman's $(1983,2012)$ lack of fit framework explicates that the role expectations that portray men as agentic and women as communal cause gender bias and impose barriers for women to gain success in male-typed positions and occupations. To date, the lack of fit framework has been largely applied to 
understand gender bias in female leadership from an evaluator's perspective (e.g., recruitment and selection processes; Heilman \& Caleo, 2018; Heilman et al., 2015). Less empirical research has focused on a target's perspective. The current work adds to the knowledge base by taking such target perspective on female academics' lack of fit. The purpose is to show that lack of fit is not only something that others see and bias their views on women's suitability for promotion or leadership, but that it is also something that women themselves see and internalize in their self-concept. Lack of fit may thus act as a self-fulfilling prophecy (or 'self-limiting behaviors' as Heilman pointed to in 1983), in the sense that women themselves start to believe that a career in academia is not for them.

Environments that inhibit people's self-concept, thwart personal goals, or signal stigma in relation to group membership contribute to a lack of psychological fit. According to Schmader and Sedikides (2018), psychological fit comes in different forms, varying from state-like and motivational (goal fit) to more trait-like and cognitive (self-concept fit). With respect to the first, recent experiments show that motivating female college students to self-present in a masculine way (rather than a more gender-neutral way) to obtain a science laboratory position, undercut their sense of authenticity, and perceived fit to the position (Dormanen et al., 2020). Also, the higher women's self-reported feelings of lack of fit in a masculine occupational domain, the lower their career motivation and persistence (Peters et al., 2012, 2013). Different from this work, we focus on cognitive self-concept fit. Lack of self-concept fit occurs when there is incongruence between perceptions about chronically accessible aspects of the self-concept (e.g., who I am as a woman, as professional) relative to an entire work domain or context (e.g., the stereotype of the successful academic; Schmader \& Sedikides, 2018; Van Veelen et al., 2016). We expect that the highly agentic occupational stereotype of the successful academic is more incongruent with the selfconcept of women compared to men (cf., Eagly \& Karau, 2002), thus resulting in higher cognitive lack of fit among female academics.

Lack of fit on agency is likely also more pronounced among assistant professors at lower ranks compared to full professors at the highest rank. The psychological distance between the current and the future professional self as portrayed by a highly agentic prototypical image of success is larger for those who have not yet obtained such success relative to those who embody that success (Peters et al., 2012). Therefore, we expect higher lack of fit between female academics' professional self-concept and the agentic stereotype of success compared to male academics, particularly at the lowest ranks (i.e., assistant professor; Hypothesis 3).

\section{Consequences of lack of fit for work and career outcomes in academia}

Female academics' higher lack of fit is expected to have negative consequences for work and career outcomes. Building from social identity theory (Tajfel \& Turner, 1979), professional identification reflects the extent to which being an academic is a central part of the self-concept and provides a sense of selfdefinition and self-esteem (Ashforth et al., 2008; Ellemers et al., 2002; Haslam \& Ellemers, 2005). The more cognitive overlap between the self and stereotypical group traits (i.e., more fit), the higher group members' identification (Latrofa et al., 2010; Van Veelen et al., 2016). However, group members who hold a minority or low-status position (such as women at lower ranks in academia), typically perceive themselves as less similar relative to stereotypical group standards, which can impede their sense of group belonging and self-esteem (Van Veelen et al., 2013). Therefore, to the extent that women's lack of fit with the agentic occupational stereotype is higher than men's, we expect this to lower professional identification, lower self-confidence as an academic (i.e. career efficacy; Hackett \& Betz, 1981), and increase intentions to leave academia (i.e., career exit; Bentein et al., 2005).

In addition to the extent that women's lack of fit with the agentic occupational stereotype of success higher than men's, this is likely to contribute to higher work exhaustion and lower work engagement (Schaufeli et al., 2002). For low-status group members (i.e., such as women in academia) not being able to be one's true self at work or having the feeling that one has to adjust to a male-dominant standard in order to 'fit in' is cognitively depleting, it lowers well-being (e.g., Bourguignon et al., 2020; Van Veelen 
et al., 2020; Veldman et al., 2021), and it leaves less energy to actually invest in the work itself. Taken together, we hypothesize that female academics' higher lack of fit with the agentic stereotype of success (relative to men's) has negative consequences for work (i.e., work engagement and exhaustion) and career (i.e., professional identification, career efficacy, and career exit intentions) outcomes, particularly among female assistant professors (Hypothesis 4).

\section{METHOD}

\section{Participants}

In the academic year 2017/18, $N=12,414$ academics from 14 Universities in the Netherlands were approached to participate in an online survey called 'Working in Academia'. A total of $N=4295$ academics responded to the questionnaire (response rate of 35\%). The following exclusion criteria were applied: (1) the participants who did not provide active informed consent or permission to use the data for scientific purposes (2) academics who did not fall in one of the academic ranks of Assistant Professor, Associate Professor, or Full Professor (e.g., PhD's or Post docs); (3) Academics who did not self-identify as man or woman, and (4) academics older than 67 years (retirement age in 2018, according to the Collective Labour Agreement of Dutch Universities). After applying the criteria, $N=3,978$ participants remained in the dataset for further analyses (Table S1). See supplement on representativeness of the sample relative to the population.

The research had a cross-sectional design. The sample consisted of $n=2363$ men (59\%) and $n=1615$ women (41\%). In terms of academic rank, $n=2034$ (51\%) were Assistant Professor, $n=877$ (22\%) were Associate Professor, and $n=1067$ (27\%) were Full Professor. Signalling the leadership gap in academia, women were relatively overrepresented at the lowest academic rank, and underrepresented at the highest rank. Among women, 63\% were Assistant Professor (relative to 43\% of men), 20\% were Associate Professor (relative to $23 \%$ of men), and $17 \%$ were Full Professor (relative to $34 \%$ of men).

Men in the sample were older $(M=48.92, S D=9.87)$ than women $(M=44.41, S D=9.12)$, $t(3900)=14.45, p<.001$, also in terms of academic age (i.e., years since obtaining a $\mathrm{PhD}$ degree; $\left.\left.M_{\text {men }}=17.02, S D=9.27 ; M_{\text {women }}=12.15, S D=7.56\right) ; t(3833)=17.19, p<.001\right)$. Most academics $(82 \%)$ held a permanent contract. Signalling their higher job insecurity, women $(22 \%)$ more often held a fixedterm contract than men $(16 \%)$. The vast majority $(82 \%)$ of academics worked fulltime $(36 \mathrm{~h}$ a week or more). Moreover, women more often held part-time contracts than men $(26 \%$ of women compared to $13 \%$ of men). Finally, academics were categorized into one of eight academic disciplines based on the NARCIS-classification (Table S1). Female and male academics were not equally represented across disciplines: For example, within the group of women, most were employed in the Humanities (20\%) and Behavioural Sciences (20\%) while the least were employed in Economics and Business (7\%). By contrast, within the group of men, most were employed in Natural Sciences and Technology (32\%) while the least were employed in the Behavioural Sciences (7\%).

\section{Procedure}

The study was approved by the Ethics Committee of the Faculty of Social and Behavioral Sciences of the university (FETC17-010). All academics in the relevant academic ranks (i.e., assistant/associate/ full prof.) were approached via their university email address through internal HR communication systems. The invitation email was signed by either the Rector or HR-director of the university. The survey was available both in Dutch and in English and online for 2-3 weeks; after 1 week a reminder email was sent out. The participants first agreed to an informed consent form, ensuring amongst others, anonymity, voluntary nature of participation, safety of data storage, the right to withdraw, and contact information, followed by questions about demographic and job characteristics. Then, 
questions about work circumstances were answered (e.g., time for research, availability of resources) as part of the larger project (LNVH, 2019). Finally, professional self-ratings and stereotype-ratings on the successful academic were measured, followed by questions about work well-being and future career in academia.

It took 15-20 min to complete the survey. Respondents did not receive a reward for their participation. Post hoc sensitivity analyses on the most comprehensive statistical model (i.e., H4) within the smallest subgroup (i.e., associate professors $N=771$ ) indicated that the study was sufficiently powered to detect small effect sizes (e.g., Cohen's $f^{2} \geq 0.013 ; \alpha=0.05,1-\beta=0.80$, Faul et al., 2009).

\section{Measures}

\section{Agentic and communal attributions of the self and the occupational stereotype}

The participants first rated their professional self and then the prototypical successful academic in their field on agentic and communal traits. Items to measure communal and agentic trait attributions were selected from pre-existing, validated scales (Abele, 2003; Bem, 1974; Cejka \& Eagly, 1999) and adapted to the context of Dutch academia based on prior empirical research (Bleijenbergh et al., 2013; Van den Brink \& Benschop, 2012 ${ }^{3}$. All trait ratings were measured on a 5-point Likert-scale ( $1=$ totally not applicable; 5 = totally applicable).

Seven items measured agentic trait-ratings (e.g., performance-oriented, self-confidence; $\alpha_{\text {self-rating }}=.72 ; \alpha_{\text {occupational stereotype }}=.79$ ) and seven items measured communal trait-ratings (e.g., being a pleasant colleague, being helpful; $\left.\alpha_{\text {self-rating }}=.76 ; \alpha_{\text {occupational stereotype }}=.92\right)$. Two CFA's on self- and stereotype ratings confirmed the validity of the 2 -factor structure of the items (agency and communality) showing good model fit (Table S2). Mean scores were computed to construct four variables measuring self- and stereotype-attributions on agentic and communal traits.

\section{Lack of fit index}

To calculate a lack of fit index on agency, agentic self and stereotype trait-ratings were averaged into 2 mean composite scores. The mean score of agentic self-attributions was subtracted from stereotype-attributions (see Derks et al., 2011; Faniko et al., 2017 for similar approaches). Positive scores indicated that traits apply more strongly to the occupational stereotype than to the self, and vice versa for negative scores. The agentic lack of fit index ranged from -2.71 to $3.57(M=0.69$, $S D=0.76)$ and the positive mean score indicated that academics generally considered themselves to be less agentic than the stereotypical successful academic, $t(3628)=54.70, p<.001,95 \% \mathrm{CI}_{95 \%}$ $(0.663 ; 0.712)$.

\section{Work and career outcomes}

We measured work engagement (six items; $\alpha=.89$ ) and exhaustion (four items; $\alpha=.84$ ) based on Schaufeli et al. (2002). Furthermore, we measured professional identification (four items; $\alpha=.82$; Ellemers et al., 2002), career efficacy (three items; $\alpha=.67$; [Hackett $\&$ Betz, 1981]), and exit intentions (two items; $r$ [3616] $=.693, p<.001$; adapted from Bentein et al., 2005). All items were measured on a 5 point Likert-type scale $(1=$ totally disagree; $5=$ totally agree). A CFA on the 19 items in total confirmed

\footnotetext{
${ }^{3}$ We also consulted the competence profiles described in the job classification system (UFO) of the Association of Universities in the Netherlands (VSNU) at https://www.vsnu.nl/en_GB/job_classification_ufo.html and https://www.vsnu.nl/files/documenten/CAO/Koppe ling_CINU_aan_UFO-profielen.pdf
} 
the validity of the 5-factor structure showing good model fit (Table S3). Mean scores were computed to construct five variables.

\section{Analytic strategy}

SPSS 24 and MPLUS 8 statistical software programs were used for data-analyses. We used an $\alpha$ level of .05 (two-tailed) for all statistical tests. To adhere to ethical concerns, it was possible for the participants to not answer questions should they wish so. Answers to questions about gender (woman/man) and rank (assistant prof./associate prof./full prof.) were a prerequisite to be included for analyses. Yet due to its voluntary nature, we did deal with missing data on covariates and dependent variables (see Supplement on how we handled missing data). For inferential statistics, we included the covariates academic age (both linear and quadratic effects), academic discipline (seven dummy variables), contract type (fixed-term/permanent), and contract size (part-time/fulltime), to ensure that the statistical evidence for gender differences and interpretation of effect sizes could not be (partially) attributed to a priori gender differences in tenure, contract, or discipline (Simpson, 1951; Table S4).

To test H1-2, two repeated measures ANCOVA's were performed with gender (man/woman) and rank (assistant/associate/full professor) as between-subject factors, and trait domain (agentic/communal) about the occupational stereotype (H1) and the professional self (H2) as within-subject factor. To test H3, a two-way ANCOVA was performed on the lack of fit index on agency, with gender (man/ woman) and rank (assistant/associate/full professor) as between-subject factors (Tables S5-S7 for ANCOVA Table H1- $3^{4}$ ). To test Hypothesis 4, a multi-group path model was tested in MPLUS to investigate the indirect effect of gender on work and career outcomes via lack of fit. To test whether the consequences of lack of fit among female compared to male academics were moderated by rank, we applied multigroup modelling. Parameter estimates for the three ranks were thus estimated separately as with moderation analyses (See Table S8).

\section{RESULTS}

This research aims to empirically demonstrate cognitive lack of fit between academics' self-image and the agentic occupational stereotype of success, depending on gender (man/woman) and rank (assistant/ associate/full professors), and to investigate consequences of lack of fit for work and career outcomes (See Table 1 for descriptive statistics and correlations).

\section{Is the occupational stereotype of academic success more agentic than communal (Hypothesis 1)?}

In support of H1, results showed that when asked to rate the stereotypical successful academic, regardless of their gender, academics emphasized agentic traits $(M=4.230, S E=.011)$ over communal traits $(M=3.271, S E=.017), F(1,3611)=63.221, p<.001, \eta_{p}^{2}=.017$. As depicted in Figure 1 (Table S5), a significant interaction between trait domain (agency vs. communality) and rank, $F(2,3611)=41.117$, $p<.001, \eta_{p}^{2}=.022$ revealed that academics reported the occupational stereotype of success to be more agentic the lower their $\operatorname{rank}\left(M_{\text {assist }}=4.309 ; S E_{\text {assist }}=0.015 ; M_{\text {associate }}=4.240, S E_{\text {associate }}=0.021\right.$; $\left.M_{\text {fullprof }}=4.140, S E_{\text {fullprof }}=0.023\right), F(2,3611)=16.090, p<.001, \eta_{p}^{2}=.009$. Conversely, academics re-

\footnotetext{
${ }^{4}$ Sample sizes across the six groups in the 2 (gender) $\times 3$ (rank) design were not equal. Checking ANOVA assumptions of normality and equality of variance across groups is thus important. Inspection of the data showed that SD's across groups were largely similar and never exceeded the largest $S D<2 *$ smallest $S D$ rule. Graphical inspection of histograms showed that dependent variables were normally distributed.
} 


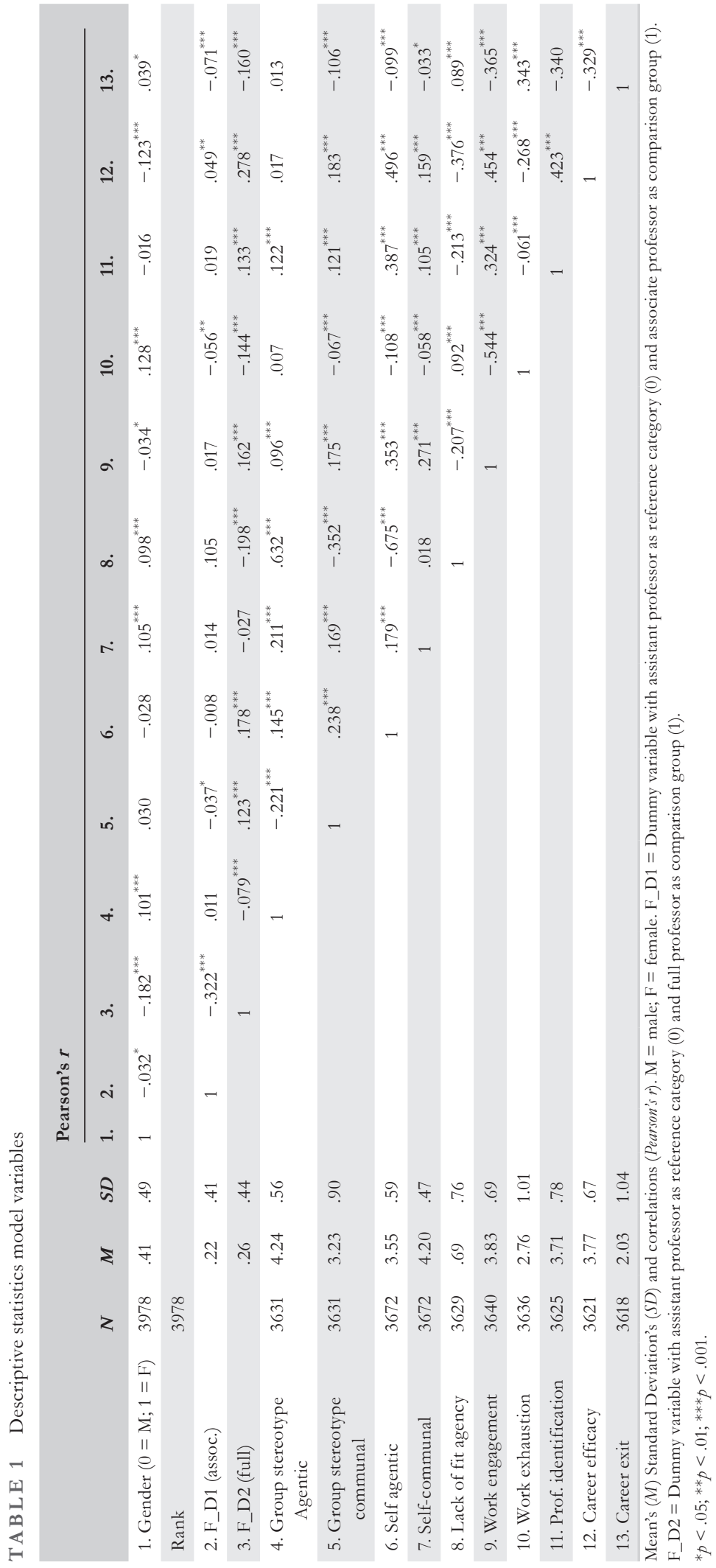




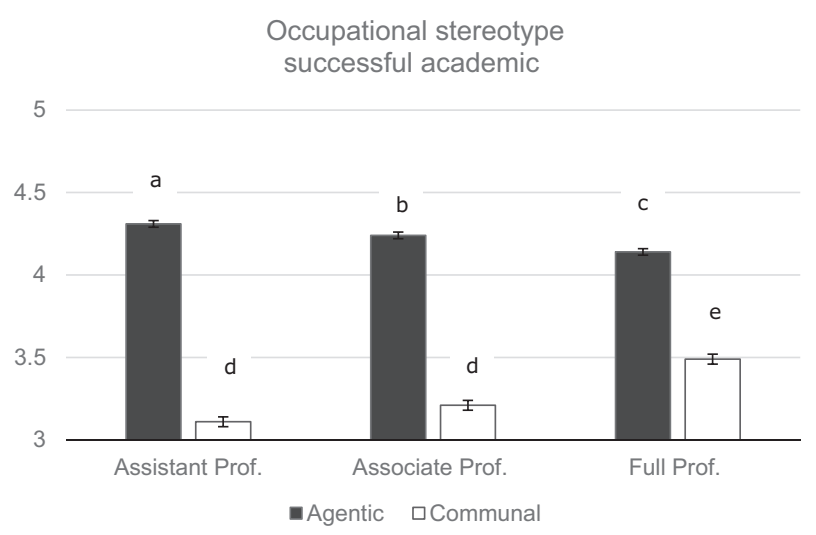

F I G U RE 1 Occupational stereotype successful academic as function of trait domain and rank. Note: Error bars represent Standard Errors (SE). Likert scale (1-5) was cropped from 3 onwards scale (3.0-5). Bars with different labels (e.g. a, b, c) indicate that pairwise comparisons (Sidak-adjusted) were significantly different at the $p<.050$ level, while no significant differences were observed for bars with the same label (e.g., d)

ported the occupational stereotype of success to be less communal at the lower $\left(M_{\text {assist }}=3.111\right.$, $\left.S E_{\text {assist }}=0.015 ; M_{\text {associate }}=3.207, S E_{\text {associate }}=0.034\right)$ compared to the highest rank $\left(M_{\text {fullprof }}=3.494\right.$, $\left.S E_{\text {fullprof }}=0.036\right), F(2,3611)=33.710, p<.001, \eta_{p}^{2}=.018$.

\section{Do academics' professional self-descriptions differ across gender and rank? (Hypothesis 2)}

Second, in contrast to the occupational stereotype, academics described themselves to be more communal $(M=4.195 ; S E=.009)$ than agentic $(M=3.604, S E=.011), F(1,3652)=23.666, p<.001$, $\eta_{p}^{2}=.006$. Confirming Hypothesis 2, both female and male academics described the self as more agentic with every step up in academic $\operatorname{rank}\left(M_{\text {assist }}=3.418, S E_{\text {assist }}=0.015 ; M_{\text {associate }}=3.586, S E_{\text {associate }}=0.022\right.$; $\left.M_{\text {fullprof }}=3.809, S E_{\text {fullprof }}=0.023\right), F(2,3652)=81.738, p<.001, \eta_{p}^{2}=.043$. Conversely, academics described the self as significantly less communal at the highest $\left(M_{\text {fullprof }}=4.152 ; S E_{\text {fullprof }}=0.019\right)$ compared to the lowest $\left(M_{\text {assist }}=4.229 ; S E_{\text {assist }}=0.015\right)$ rank, $F\left(2,3652=4921, p=.007, \eta_{p}^{2}=.003\right.$, although this latter effect size was much smaller (Table S6).

The three-way interaction between trait domain (agentic/communal), gender (man v/woman), and rank (assistant vs. associate vs. full prof.) was also significant, $F(2,3652)=5.665, p=.003, \eta_{p}^{2}=.003$ (see Figure 2). Self-ascribed agency was higher with every step up in rank among both female, $F(2,1483)=32.600, p<.001, \eta_{p}^{2}=.042$, and male academics, $F(2,2156)=51.267, p<.001, \eta_{p}^{2}=.045$ However, while for male academics, self-ascribed communality did not differ depending on rank, $F(2,2156)=0.41, p=.662, \eta_{p}^{2}=.000$, for female academics, self-ascribed communality was lower at higher ranks, $M_{\text {assist }}=4.291, S E_{\text {assist }}=0.016 ; M_{\text {associate }}=4.236, S E_{\text {associate }}=0.028 ; M_{\text {fullprof }}=4.150$, $S E_{\text {fullprof }}=0.033, F(2,1483)=6.215, p=.002, \eta_{p}^{2}=.008$

Examining contrasts between men and women at different academic ranks (Figure 2), we found that female assistant professors described themselves as more communal $(M=4.264, S E=.016)$ than their male peers $(M=4.142$, SE $=.16), F(1,1877)=27.878, p<.001, \eta_{p}^{2}=.015$, while no significant gender differences were found for agentic self-ratings, $F(1,1877)=1.322, p=.250, \eta_{p}^{2}=.001$. A similar, yet less pronounced pattern of results was visible for associate professors. In contrast, female full professors described themselves as most agentic $(M=4.206$; $S E=.030)$ - even significantly more so than their male peers $(M=3.795 ; S E=.037), F(1,966)=4.264, p=.039, \eta_{p}^{2}=.004$, while no significant gender differences were found for communal self-ratings, $F(1,966)=1.283, p=.258, \eta_{p}^{2}=.001$. 


\section{Professional self-ratings}

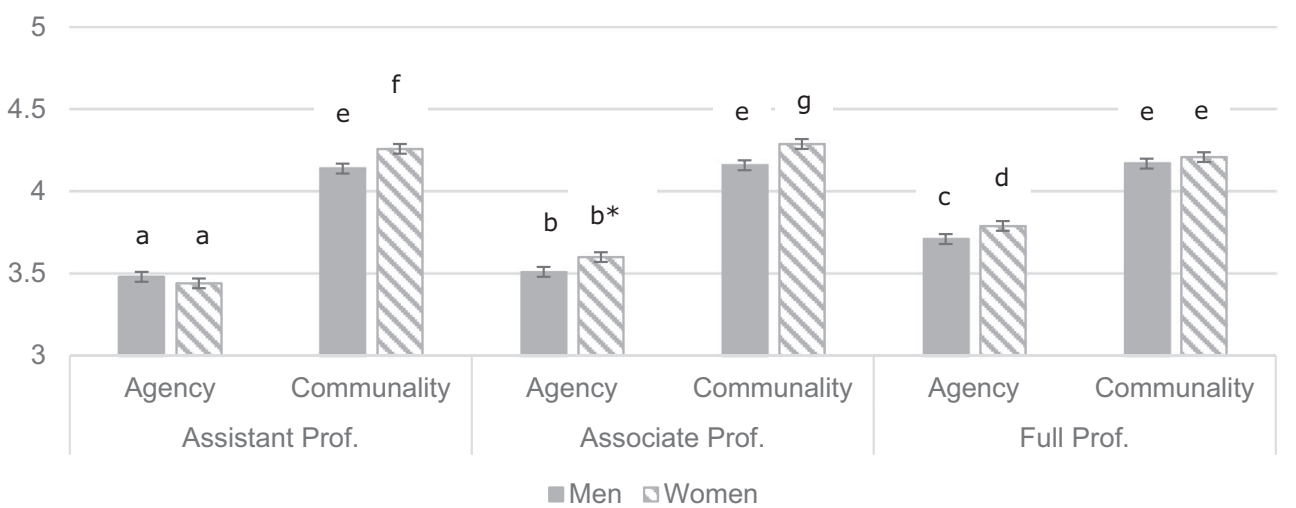

F I G U R E 2 Professional self-ratings as a function of gender and rank.

Note: Error bars represent Standard Errors (SE). Likert scale (1-5) was cropped from 3 onwards scale (3.0-5). Bars with different labels indicate that pairwise comparisons (Sidak-adjusted) were significantly different at the $p<.050$ level, while no significant differences were observed for bars with the same.). ${ }^{*}$ Among associate professors, the gender difference in agentic self-description was marginally significant, such that female associate professors $(M=3.597 ; S E=.035)$ described themselves as slightly more agentic compared to their male peers $(M=3.510, S E=.26), F(1,783)=3.652, p=.056,=.005$

\section{Do early career female academics experience most lack of fit with the agentic occupational stereotype? (Hypothesis 3)}

Third, results from the ANCOVA showed that, after correction for the covariates, gender, and rank and their interaction term explained $8 \%$ of the variance in lack of fit on agency, $R^{2}=.076, F(18,3610)=16,55$, $p<.001$. As depicted in Figure 3 (Table S7), lack of fit was higher among academics at the lowest compared to the higher academic ranks. Assistant professors reported higher levels of lack of fit $(M=0.89$, $S E=.02)$, than associate professors $(M=0.65, S E=.03)$, and full professors $(M=0.33, S E=.03)$, $F(2,3610)=103.47, p<.001, \eta_{p}^{2}=.054$. In support for Hypothesis 3, on average, female academics re-

ported higher lack of fit $(M=0.66, S E=.02)$ than male academics $(M=0.58, S E=.02), F(1,3610)=7.038$, $p=.008, \eta_{p}^{2}=.002$. This gender effect was moderated by rank $F(2,3610)=7.122, p=.001, \eta_{p}^{2}=.004$,

such that the gender difference in lack of fit only manifested at the lowest rank (i.e., assistant professors). Specifically, confirming Hypothesis 3, female assistant professors reported the highest levels of lack of fit $(M=0.99, S E=.03)$ - significantly higher compared to male assistant professors $(M=0.79, S E=.03)$, $F(1,3610)=34.74, p<.001, \eta_{p}^{2}=.010$. No evidence for gender differences was found at the associate, $F(1,3610)=0.44, p=.507, \eta_{p}^{2}=.000$, and full professor level, $\left.F(1,3610)=0.02, p=.887, \eta_{p}^{2}=.000\right)$.

\section{Is lack of fit among early career female academics related to work and career outcomes? (Hypothesis 4)}

A multi-group path model was tested to investigate the consequences of female (compared to male) academics' lack of fit for their work and career outcomes, moderated by academic rank. We built the conceptual model by modelling regression paths from gender $(0=$ men; $1=$ women; IV $)$ to the agency lack of fit index (M), and from lack of fit (M) to all DV's. The covariates were modelled both on the mediator and the dependent variables. The DV's were allowed to covary to control for multicollinearity. To investigate the direct paths in the model, standardized parameter estimates were interpreted. 


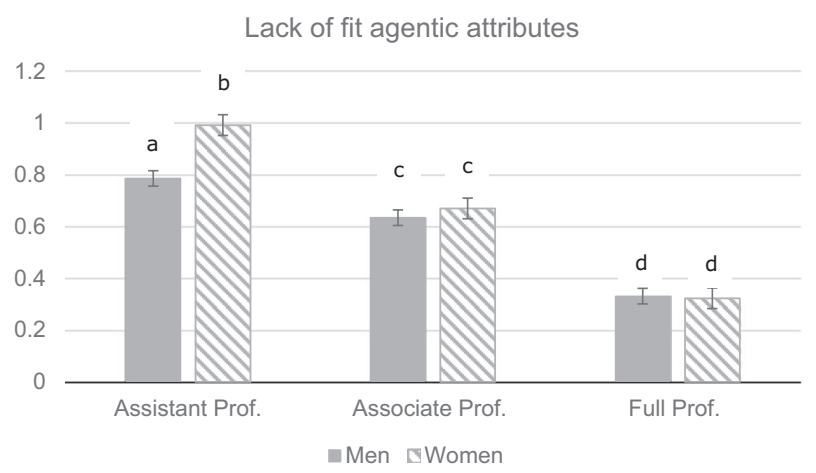

F I G U RE 3 Lack of fit between the self and the agentic occupational stereotype as a function of gender and rank. Note: Error bars represent Standard Errors (SE). Bars with different labels (e.g., a, b, c) indicate that means are significantly different at the $p<.050$ level, while no significant differences were observed for bars with the same (e.g., d) labels. The lack of fit index on the y-axis should be interpreted as occupational stereotype-ratings minus self-ratings on agentic attributes (i.e., perceiving the self as less agentic than the stereotype)

We tested indirect effects by generating $95 \%$ bootstrapped confidence intervals $\left(\mathrm{CI}_{95 \%} ; 5000\right.$ iterations; MacKinnon et al., 2004; Shrout \& Bolger, 2002).

First, the hypothesized multi-group path model (Model 1; Figure 4) yielded good model fit, $\chi^{2}(15)=84.43, p<.001$, RMSEA $=.062$, SRMR $=.007$, CFI $=.985$, TLI $=.697$. Second, we tested whether multigroup modelling based on rank was justified, by comparing the model fit of the unconstrained multigroup model (Model 1), where the parameter estimates between the model variables were allowed to vary across ranks ( 1 = Assistant Prof.; 2 = Associate Prof., $3=$ Full Prof.), to a model where the paths were constrained (i.e., where parameter estimates are held constant across rank, assuming that there are no differences between groups; Model 2). The constrained model, $\chi^{2}(183)=313.25, p<.001$, yielded worse fit than the unconstrained model, $\Delta \chi^{2}(168)=228.82$, $p=.001$. This indicated that the parameter estimates were significantly different across ranks and multigroup modelling was justified. To test Hypothesis 4, we thus interpreted the standardized parameter estimates for the unconstrained Model 1, and calculated Wald's difference test to determine which direct and indirect effects were significantly different across ranks (Table S8). The explained variance $\left(R^{2}\right)$ per outcome variable at each academic rank is depicted in Figure 4. Note that for assistant professors, explained variance for all outcome measures was statistically significant, varying from small $(2 \%)$ to medium (14\%). For example, among assistant professors gender accounted for $6 \%$ of variance in lack of fit.

At all academic ranks, the higher academics' lack of fit with the agentic occupational stereotype the lower their reported work engagement, professional identification, and career confidence in academia (Figure 4). Moreover, specifically for assistant and associate professors, higher lack of fit resulted in higher levels of work exhaustion and a higher intention to leave academia. Confirming Hypothesis 4, only among early career assistant professors, the indirect effects from gender to work and career outcomes via lack of fit were significant. Namely, to the extent that female assistant professors' lack of fit was significantly higher than their male peers, this negatively affected their work and career outcomes. Only among assistant professors, higher lack of fit among women compared to men, resulted in women's significantly lower work engagement (indirect effect: $=-.03, S E=.006, p<.001$, CI 95\% -0.04/-0.02), higher work exhaustion levels (indirect effect: $=.01, S E=.004, p=.004, \mathrm{CI}$ $95 \% 0.01 / 0.02$ ), lower professional identification (indirect effect: $=-.03, S E=.0046, p<.001, \mathrm{CI} 95 \%$ $-0.04 /-0.02$ ), lower career efficacy (indirect effect: $=-.05, S E=.009, p<.001$, CI 95\% $-0.07 /-0.03$ ), and a higher in intention to leave academia (indirect effect: $=.01, S E=.004, p=.015, \mathrm{CI} 95 \% 0.002 / 0.02$ ) relative to men's. 


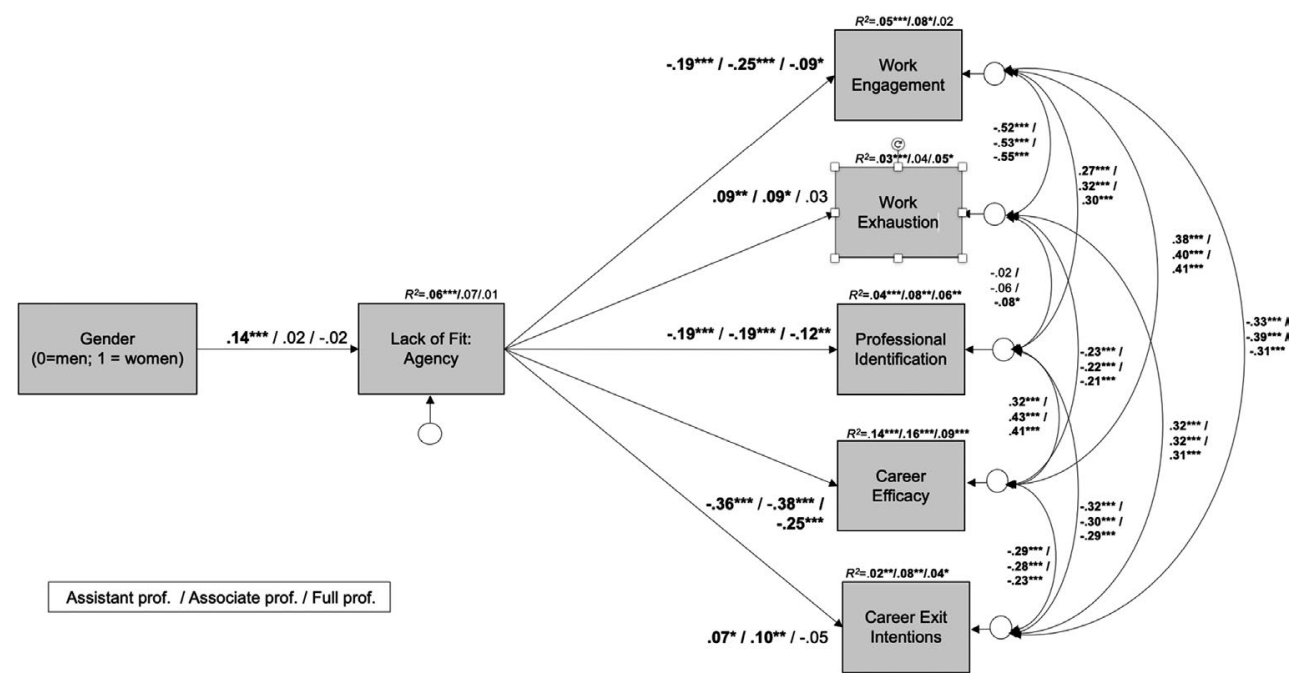

F I G U R E 4 Multigroup path model on consequences lack of fit for male and female academics' work and career outcomes. Note: Standardized Parameter Estimates between model variables are displayed for Assistant/Associate/Full Professors separately. Estimates marked in bold are statistically significant at either ${ }^{* *} p<.001,{ }^{* *} p<.010,{ }^{*} p<.050$. Explained variance for dependent variables $\left(R^{2}\right)$ per academic rank is depicted above the box

\section{GENERAL DISCUSSION}

The current research demonstrates that in academia, the subtle psychological process of cognitive lack of fit with a highly agentic 'superhero' standard of success (e.g., being self-confident, self-focused, and competitive) forms yet another gender gap that threatens career advancement in academia, particularly among women at an early career stage. Specifically, female (relative to male) assistant professors' higher lack of fit was related to lower work well-being, lower professional identification and career efficacy, and a stronger intention to leave academia. Lack of fit effects was found above and beyond a priori gender differences in academics' employment conditions. While effect sizes in our data were generally small, they do confirm the intangible and pervasive nature of gender bias, and its subtle manifestations in many areas in academia. Insights from this research are valuable and timely both theoretically, further unravelling the socio-cognitive barriers to professional identity formation among low-status groups (i.e., women in academia), and practically, given current debates on how academia's narrowly-defined, agentic culture of excellence breeds social inequality in academic careers (Ellemers, 2021; Woolston, 2021).

Our results showed that academics who embody career success themselves (i.e., full professors at the highest ranks), showed most fit between the self and the agentic occupational stereotype of success. In fact, female full professors considered themselves to be most agentic - significantly more so compared to their male peers and to those lower in rank. This confirms earlier demonstrations of Queen Bee behaviours, where self-portraying as highly agentic is considered a coping strategy for women leaders to be accepted in male-dominated high-status positions (e.g., Derks et al., 2016; Faniko et al., 2021). Stronger agentic self-descriptions at higher academic ranks could be either be due to processes of (self-)selection (i.e., the more agentic academics are, the more likely they are to receive (or apply for) a promotion) or socialization (i.e., academics learn that higher academic ranks require them to be more agentic), or both. Future longitudinal studies on women's academic career trajectories could shed more light on this.

Explorative analyses showed that for women, communal self-descriptions declined with every step up in academic rank - no such differences were observed for men. This may be a signal that apart from adhering to the agentic prototype of success, for women it may also require a distancing from communal 
traits associated with one's gender identity to successfully climb the rungs of the academic career ladder. While Queen Bee literature so far has not shown a distancing effect on communal in-group traits among women in leadership (only an assertion towards agentic out-group traits), our findings are in line with literature on identity bifurcation and separation (Pronin et al., 2004; Von Hippel et al., 2011), suggesting that gender identity aspects that do not fit the academic context may be damaging and thus rejected as women gain academic success. We encourage further research on the social mobility responses of women in masculine work contexts, to gain a more dynamic understanding of tendencies to 'pull towards' the high-status group (i.e., I am more agentic) and to 'push away' a stigmatized group (i.e., I am not as communal; Van Veelen et al., 2020).

Our data also showed an interesting contrast effect: In their professional self-descriptions, academics indicated to be more communal than agentic, while they saw the occupational stereotypical of success as more agentic than communal. This contrast effect was particularly pronounced among early career assistant professors. We could speculate as to why we find this contrast effect. Perhaps it is due to selection bias, because the pro-social academics who were willing to fill out a survey voluntarily are more communal than agentic by nature. Or perhaps it is due to the items themselves, such that self-describing as 'collegial' and 'concerned for others' (i.e., communal) is more socially desirable than self-describing as 'self-focused' and 'competitive' (i.e., agentic), while such social desirability concerns do not apply for external attributions (e.g., occupational stereotype). But perhaps most convincingly to the context of this study - the observed contrasts in communal and agentic self- versus stereotype-ratings may be due to a mismatch in what, particularly early career academics perceive as the traits needed to actually do their job well (namely collaborating with others, exchanging knowledge with peers, students, and society) versus how they are currently rewarded and acknowledged for academic success (namely with self-focus and in competition with others; see Ellemers, 2021). Indeed, many academic systems and corresponding funding bodies do not yet sufficiently reward the collaborative nature of academic work.

Although correlational, our findings suggest that lack of fit with the agentic stereotype of academic success threatens the well-being and sustainability of careers of early-career academics, and particularly female assistant professors. Indeed, lack of fit is likely most detrimental when academics are still in a precarious and vulnerable position and when, particularly for women, 'doing things differently' than the agentic norm prescribes does not seem like a viable option in order to have a chance at full professorship (Kachchaf et al., 2015). Expanding this research to academics at even earlier career phases (i.e., $\mathrm{PhD}$ and post-doctoral researchers) is therefore important, because their position is even more precarious (OECD, 2021). Potentially, lack of fit is even higher and might have even more detrimental consequences for their career prospects in academia.

To date, many gender diversity initiatives to improve the position of women in academia take a targeted approach to empower women to better fit with the highly agentic and male-dominant culture. Skill trainings and network events are available specifically for women in academia to learn to better self-promote on their CV's, to become tougher negotiators, or to become more confident leaders. While often well-intentioned, such a 'fix the women' approach places the onus on women and makes them responsible for resolving gender inequality. Moreover, it perpetuates the idea that academic success is based on agentic qualities and promotes the stereotype that women 'cannot negotiate', 'need extra help' or 'should become more like men' in order to advance their careers. There is accumulating evidence that a women-only approach to foster gender diversity and equality is not only often ineffective, it can even result in backlash (Crosby et al., 2014; Unzueta et al., 2010). Rather than teaching women how to fit better with the current masculine standard of success in academia, the findings in our research advocate for a systemic change. This means to change the narrowly defined standard of success, and move towards a more inclusive academic culture in which not only agentic but also communal behaviours are recognized and rewarded.

Following the guidelines of the San Francisco Declaration of Research Assessment (DORA, 2020), public knowledge institutions in the Netherlands are reformulating the system of reward and recognition in academia, with the goal to broaden the scope of what 'academic excellence' means (VSNU, 2020; Woolston, 2021). In line with the current research findings, this change in reward and recognition 
entails a move away from the highly agentic and narrow-focus on competitive research funding acquisition and number of first-authored publications, and a move towards inclusion of team science, teaching, academic leadership, and collaborative practice as evaluation criteria of academic success. We know that implicit bias causes agentic traits to be more likely recognized in male rather than female academics (Heilman, 2012; Koenig \& Eagly, 2014). Adding to that knowledge base, female academics too are less likely to recognize themselves in that agentic standard of success than men do. A more inclusive definition of academic success will create more space for diversity. And not because male and female academics are inherently different, but because when we have a more inclusive picture of what it means to be successful in academia, implicit gender biases may have less impact on (self-)selection and promotion opportunities.

Broadening the standards of academic success means that multiple career paths can be chosen towards full professorship, which may ultimately result in more diverse role models and a more inclusive academy (Mitchneck et al., 2016). Such change towards an inclusive culture in academia would not only have the potential to increase women's career opportunities in academia, therewith closing existing gender gaps, but it also offers a more diverse set of career opportunities for men. Recent studies show that not only women, but men too may experience negative consequences of highly agentic work cultures. Specifically, in highly macho, masculine, or male-dominated working cultures (e.g., The Royal Army, Police, Medical Surgeons, High-Tech, Finance), when both women and men sense that they themselves are not agentic enough to adhere to the stereotypical standard of success, this is related to lower work engagement and belonging (Peters et al., 2015; Van Veelen et al., 2019). We see the same pattern of results in our data. While lack of fit is stronger for women compared to men, it was negatively related to work and career outcomes for both women and men. As such, a narrowly defined agentic view on academic excellence could mean that we do not only lose out on unique talent of (young) women, but also men (Ellemers, 2021; Nielsen et al., 2017).

A potential methodological limitation of the current research is that the data is cross-sectional (but see Spector, 2019). Yet, this approach exactly fits our study purposes - that is to efficiently and effectively reach a large population to disentangle complex relationships among psychological variables signalling gender gaps in academia. The data offers a snapshot of what a young generation of academics (assistant professors) currently sees as the benchmark for acquiring academic success (namely a highly agentic prototype). And they are right in their perception, because current exemplars of success (full professors) have indeed internalized the agentic prototype more than a younger generation does. This results in female (more than male) assistant professors experiencing psychological misfit in how current standards of success reflect their professional self-image, obstructing them from envisioning successful career advancement in academia. The covariates in our model rule out potential spurious relationships in this design (Table S4). Nevertheless, we do need to be cautious in making causal inferences. To this end, a longitudinal research or field experiments are recommended. For example, following early career academics during career transitions or monitoring the effectiveness of initiatives to make recognition and rewards standards more inclusive in academia.

This research was carried out in the Netherlands only. A strength of the data is its ecological validity - with a sample covering 33\% of the entire target population, we can be confident that results are generalizable to the Dutch context. Also, since the Dutch academic system is representative of the Anglo-Saxon academic system in for example the United Kingdom and North-America, results are likely generalizable to these countries as well. Nevertheless, investigating differences in academic cultures cross-nationally and their consequences for (gender) diversity are recommended.

This research took a holistic approach to demonstrate a gender gap in lack of fit in agency, above and beyond potential differences academic discipline. A focus on academic subdisciplines was beyond the scope of the research goals, also because in terms of statistical power, sample sizes among female full professors would be too small to render reliable interpretation of interaction-terms with discipline. Nevertheless, we recognize that academic cultures differ across disciplines (Ceci et al., 2014; Derks et al., 2018). In future research, it is important to dive deeper into those subcultures and their connection to socio-psychological parameters of gender gaps in academia. 
To conclude, this study sampled among the entire population of assistant/associate/full professors in the Netherlands, demonstrate that female early career academics show the highest cognitive lack of fit with the agentic 'superhero' stereotype of academic success. Our socio-cognitive approach to lack of fit forms yet another, subtle but pervasive gender gap that obstructs women's professional identity formation and career prospects in academia. Broadening the standards of academic success (including both agency and communality) and offering more diverse career trajectories towards full professorship, may ultimately result in a more (gender) inclusive academy.

\section{ACKNOWLEDGEMENTS}

The authors thank the Dutch Network of Women Professors, and particularly Lidwien Poorthuis for all her support in and contribution to survey development and administration on a nation-wide level and for involving all HR directors of the Universities in the Netherlands. They thank Elena Bacchini for programming the survey in Qualtrics. This research was supported by funding from the Dutch Network of Women Professors awarded to Belle Derks, and by an NWO VIDI grant (016.155.391) awarded to Belle Derks.

\section{CONFLICTS OF INTEREST}

All authors declare no conflict of interest.

\section{AUTHOR CONTRIBUTION}

Ruth Van Veelen: Conceptualization (equal); Data curation (equal); Formal analysis (equal); Investigation (equal); Methodology (equal); Project administration (equal); Resources (equal); Visualization (equal); Writing - original draft (equal); Writing - review \& editing (equal). Belle Derks: Conceptualization (equal); Funding acquisition (equal); Methodology (equal); Project administration (equal); Supervision (equal); Writing - review \& editing (equal).

\section{DATA AVAILABILITY STATEMENT}

The data are not publicly available due to privacy or ethical restrictions, for example, containing information that could compromise the privacy of research participants. Therefore, only the principal investigators have access to the raw data files. The anonymized data to support the findings of this study are available upon reasonable request from the corresponding author. Additional Materials (e.g., Codebooks) and SPSS and MPLUS code and output for the analyses reported in this manuscript are available in a repository at the Open Science Framework: https:/osf.io/tjz4d/

\section{ORCID}

Ruth Van Veelen (D) https://orcid.org/0000-0002-2609-1997

Belle Derks (D) https://orcid.org/0000-0002-0038-4134

\section{REFERENCES}

Abele, A. E. (2003). The dynamics of masculine-agentic and feminine-communal traits: Findings from a prospective study. Journal of Personality and Social Psychology, 85(4), 768. https://doi.org/10.1037/0022-3514.85.4.768

Ashforth, B. E., Harrison, S. H., \& Corley, K. G. (2008). Identification in organizations: An examination of four fundamental questions. Journal of Management, 34, 325-374. https://doi.org/10.1177/0149206308316059

Bagilhole, B. (2017). Being different is a very difficult row to hoe: Survival strategies of women academics. In Changing the subject (pp. 15-28). Taylor \& Francis.

Bedi, G., Van Dam, N. T., \& Munafo, M. (2012). Gender inequality in awarded research grants. The Lancet, $380(9840), 474$. https://doi.org/10.1016/S0140-6736(12)61292-6

Belle, D., Smith-Doerr, L., \& O’Brien, L. M. (2014). Gendered networks: Professional connections of science and engineering faculty. In Gender transformation in the academy (pp. 153-175) (Advances in Gender Research, Vol. 19). Emerald Group Publishing Limited. https://doi.org/10.1108/S1529-212620140000019007

Bem, S. L. (1974). The measurement of psychological androgyny. Journal of Consulting and Clinical Psychology, 42(2), 155. https:// doi.org/10.1037/h0036215 
Bentein, K., Vandenberghe, C., Vandenberg, R., \& Stinglhamber, F. (2005). The role of change in the relationship between commitment and turnover: A latent growth modeling approach. Journal of Applied Psychology, 90(3), 468. https://doi.org/1 $0.1037 / 0021-9010.90 .3 .468$

Bian, L., Leslie, S.-J., \& Cimpian, A. (2018). Evidence of bias against girls and women in contexts that emphasize intellectual ability. American Psychologist, 73(9), 1139-1153. https://doi.org/10.1037/amp0000427

Bleijenbergh, I. L., Van Engen, M. L., \& Vinkenburg, C. J. (2013). Othering women: Fluid images of the ideal academic. Equality, Diversity and Inclusion, 32(1), 22-35. https://doi.org/10.1108/02610151311305597

Bourguignon, D., Teixeira, C. P., Koc, Y., Outten, H. R., Faniko, K., \& Schmitt, M. T. (2020). On the protective role of identification with a stigmatized identity: Promoting engagement and discouraging disengagement coping strategies. European Journal of Social Psychology, 50(6), 1125-1142. https://doi.org/10.1002/ejsp.2703

Brower, A., \& James, A. (2020). Research performance and age explain less than half of the gender pay gap in New Zealand universities. PLoS One, 15(1), e0226392. https://doi.org/10.1371/journal.pone.0226392

Carli, L. L., Alawa, L., Lee, Y., Zhao, B., \& Kim, E. (2016). Stereotypes about gender and science: Womenf scientists. Psychology of Women Quarterly, 40(2), 244-260. https://doi.org/10.1177/0361684315622645

Carrigan, C., Quinn, K., \& Riskin, E. A. (2011). The gendered division of labor among STEM faculty and the effects of critical mass. Journal of Diversity in Higher Education, 4(3), 131. https://doi.org/10.1037/a0021831

Casad, B. J., Franks, J. E., Garasky, C. E., Kittleman, M. M., Roesler, A. C., Hall, D. Y., \& Petzel, Z. W. (2021). Gender inequality in academia: Problems and solutions for women faculty in STEM. Journal of Neuroscience Research, 99(1), 13-23. https://doi. org/10.1002/jnr.24631

Cech, E. A., \& Blair-Loy, M. (2019). The changing career trajectories of new parents in STEM. Proceedings of the National Academy of Sciences of the United States of America, 116(10), 4182-4187. https://doi.org/10.1073/pnas.1810862116

Ceci, S. J., Ginther, D. K., Kahn, S., \& Williams, W. M. (2014). Women in academic science: A changing landscape. Psychological Science in the Public Interest, 15(3), 75-141. https://doi.org/10.1177/1529100614541236

Ceci, S. J., \& Williams, W. M. (2011). Understanding current causes of women's underrepresentation in science. Proceedings of the National Academy of Sciences of the United States of America, 108(8), 3157-3162. https://doi.org/10.1073/pnas.1014871108

Cejka, M. A., \& Eagly, A. H. (1999). Gender-stereotypic images of occupations correspond to the sex segregation of employment. Personality and Social Psychology Bulletin, 25(4), 413-423. https://doi.org/10.1177/0146167299025004002

Center for Global Development. (2019). Mind the gap: 5 Facts about the gender gap in education. Retrieved from https://www. cgdev.org/blog/mind-gap-5-facts-about-gender-gap-education

Cheryan, S., Master, A., \& Meltzoff, A. N. (2015). Cultural stereotypes as gatekeepers: Increasing girls' interest in computer science and engineering by diversifying stereotypes. Frontiers in Psychology, 6, 49. https://doi.org/10.3389/fpsyg.2015.00049

Collins, R., \& Steffen-Fluhr, N. (2019). Hidden patterns: Using social network analysis to track career trajectories of women STEM faculty. Equality, Diversity and Inclusion, 38(2), 265-282. https://doi.org/10.1108/EDI-09-2017-0183

Crabtree, S., \& Shiel, C. (2019). "Playing Mother": channeled careers and the construction of gender in academia. Sage Open, 9(3), 1-14. https://doi.org/10.1177/2158244019876285

Crosby, J. R., King, M., \& Savitsky, K. (2014). The minority spotlight effect. Social Psychological and Personality Science, 5(7), 743-750. https://doi.org/10.1177/1948550614527625

Derks, B., Ellemers, N., Van Laar, C., \& De Groot, K. (2011). Do sexist organizational cultures create the Queen Bee? British Journal of Social Psychology, 50(3), 519-535. https://doi.org/10.1348/014466610X525280

Derks, B., Van Laar, C., \& Ellemers, N. (2016). The queen bee phenomenon: Why women leaders distance themselves from junior women. The Leadership Quarterly, 27(3), 456-469. https://doi.org/10.1016/j.leaqua.2015.12.007

Derks, B., Van Veelen, R., \& Handgraaf, M. (2018). Successful economists are highly masculine. In ESB dossier women in economics (pp. 16-19). Economisch Statistische Berichten. Retrieved from https://esb.nu/esb/20046294/successful-economists -are-highly-masculine

Dormanen, R., Sanders, C. S., Maffly-Kipp, J., Smith, J. L., \& Vess, M. (2020). assimilation undercuts authenticity: A consequence of women's masculine self-presentation in masculine contexts. Psychology of Women Quarterly, 44(4), 488-502. https://doi.org/10.1177/0361684320947648

Eagly, A. H. (1987). Sex differences in social behavior: A social-role interpretation. Erlbaum.

Eagly, A. H., \& Karau, S. J. (2002). Role congruity theory of prejudice toward female leaders. Psychological Review, 109 (3), 573. https://doi.org/10.1037//0033-295X.109.3.573

Eagly, A. H., Nater, C., Miller, D. I., Kaufmann, M., \& Sczesny, S. (2020). Gender stereotypes have changed: A cross-temporal meta-analysis of U.S. public opinion polls from 1946 to 2018. American Psychologist, 75(3), 301-315. https://doi.org/10.1037/ amp0000494

Eagly, A. H., \& Steffen, V. J. (1984). Gender stereotypes stem from the distribution of women and men into social roles. Journal of Personality and Social Psychology, 46(4), 735. https://doi.org/10.1037/0022-3514.46.4.735

Eagly, A. H., Wood, W., \& Diekman, A. B. (2000). Social role theory of sex differences and similarities: A current appraisal. In T. Eckles, \& H. M. Trautner (Eds.), The developmental social psychology of gender (pp. 123-174). Lawrence Erlbaum Associates Publishers.

El-Alayli, A., Hansen-Brown, A. A., \& Ceynar, M. (2018). Dancing backwards in high heels: Female professors experience more work demands and special favor requests, particularly from academically entitled students. Sex Roles, 79, 136-150. https:// doi.org/10.1007/s11199-017-0872-6 
Ellemers, N. (2018). Gender stereotypes. Annual Review of Psychology, 69, 275-298. https://doi.org/10.1146/annurev-psych-12221 6-011719

Ellemers, N. (2021). Science as collaborative knowledge generation. British Journal of Social Psychology, 60(1), 1-28. https://doi. $\operatorname{org} / 10.1111 /$ bjso.12430

Ellemers, N., Spears, R., \& Doosje, B. (2002). Self and social identity. Annual Review of Psychology, 53(1), 161-186. https://doi. org/10.1146/annurev.psych.53.100901.135228

Ellemers, N., Van den Heuvel, H., De Gilder, D., Maass, A., \& Bonvini, A. (2004). The underrepresentation of women in science: Differential commitment or the queen bee syndrome? British Journal of Social Psychology, 43(3), 315-338. https://doi. org $/ 10.1348 / 0144666042037999$

Faniko, K., Ellemers, N., \& Derks, B. (2021). The Queen Bee phenomenon in Academia 15 years after: Does it still exist, and if so, why? British Journal of Social Psychology, 60(2), 383-399. https://doi.org/10.1111/bjso.12408

Faniko, K., Ellemers, N., Derks, B., \& Lorenzi-Cioldi, F. (2017). Nothing changes, really: Why women who break through the glass ceiling end up reinforcing it. Personality and Social Psychology Bulletin, 43(5), 638-651. https://doi.org/10.1177/01461 67217695551

Faul, F., Erdfelder, E., Buchner, A., \& Lang, A. G. (2009). Statistical power analyses using G* Power 3.1: Tests for correlation and regression analyses. Behavior Research Methods, 41(4), 1149-1160. https://doi.org/10.3758/BRM.41.4.1149

Fiske, S. T., Cuddy, A. J. C., Glick, P., \& Xu, J. (2002). A model of (often mixed) stereotype content: Competence and warmth respectively follow from perceived status and competition. Journal of Personality and Social Psychology, 82, 878-902. https:// doi.org/10.1037/0022-3514.82.6.878

Hackett, G., \& Betz, N. E. (1981). A self-efficacy approach to the career development of women. Journal of Vocational Behavior, 18(3), 326-339. https://doi.org/10.1016/0001-8791(81)90019-1

Haslam, S. A., \& Ellemers, N. (2005). Social identity in industrial and organisational psychology. International Review of Industrial and Organizational Psychology, 20, 39-118. https://doi.org/10.1002/0470029307.ch2

Heilman, M. E. (1983). Sex bias in work settings: The lack of fit model. Research in Organizational Behavior, 5, $269-298$.

Heilman, M. E. (2012). Gender Stereotypes and workplace bias. Research in Organizational Behavior, 32, 113-135. https://doi. org/10.1016/j.riob.2012.11.003

Heilman, M. E., \& Caleo, S. (2018). Combatting gender discrimination: A lack of fit framework. Group Processes and Intergroup Relations, 21(5), 725-744. https://doi.org/10.1177/1368430218761587

Heilman, M. E., Manzi, F., \& Braun, S. (2015). Presumed incompetent: Perceived lack of fit and gender bias in recruitment and selection. In Handbook of gendered careers in management: ggetting in, getting on, getting out (pp. 90-104). Edward Elgar. https://doi. org/10.4337/9781782547709.00014

Hentschel, T., Heilman, M. E., \& Peus, C. V. (2019). The multiple dimensions of gender stereotypes: A current look at men's and women's characterizations of others and themselves. Frontiers in Psychology, 10, 11. https://doi.org/10.3389/fpsyg.2019.00011

Higher Education Statistics Agency. (2013). Staff at higher education institutions in the United Kingdom 2011/12. Retrieved from https:// www.hesa.ac.uk/news/17-01-2013/sfr185-staff

Hyde, J. S. (2014). Gender similarities and differences. Annual Review of Psychology, 65, 373-398. https://doi.org/10.1146/annur ev-psych-010213-115057

Judge, T. A., \& Cable, D. M. (1997). Applicant personality, organizational culture, and organization attraction. Personnel Psychology, 50(2), 359-394. https://doi.org/10.1111/j.1744-6570.1997.tb00912.x

Kachchaf, R., Ko, L., Hodari, A., \& Ong, M. (2015). Career-life balance for women of color: Experiences in science and engineering academia. Journal of Diversity in Higher Education, 8(3), 175-191. https://doi.org/10.1037/a0039068

Koenig, A. M., \& Eagly, A. H. (2014). Evidence for the social role theory of stereotype content: Observations of groups' roles shape stereotypes. Journal of Personality and Social Psychology, 107(3), 371. https://doi.org/10.1037/a0037215

Latrofa, M., Vaes, J., Cadinu, M., \& Carnaghi, A. (2010). The cognitive representation of self-stereotyping. Personality and Social Psychology Bulletin, 36(7), 911-922. https://doi.org/10.1177/0146167210373907

League of European Research Universities. (2019). Equality, Diversity and Inclusion at Universities: The power of a systemic approach. Retrieved from https://www.leru.org/publications/equality-diversity-and-inclusion-at-universities

Leslie, S.-J., Cimpian, A., Meyer, M., \& Freeland, E. (2015). Expectations of brilliance underlie gender distributions across academic disciplines. Science, 347(6219), 262-265. https://doi.org/10.1126/science.1261375

LNVH. (2016). Financiële beloning van mannen en vrouwen in de wetenschap. [Financial rewards of men and women in Academia]. Dutch Network of Women Professors (LNVH). Retrieved from https://www.scienceguide.nl/wp-content/uploads/2019/03/ fin-beloningen-lnvh-2016.pdf

LNVH. (2019). Verborgen verschillen in werktaken, hulpbronnen en onderhandelingen over arbeidsvoorwaarden tussen vrouwelijke en mannelijke wetenschappers in Nederland. [Hidden differences between male and female academic staff at Dutch universities in terms of tasks, access to resources and negotiation of employment terms]. Dutch Network of Women Professors (LNVH). Retrieved from https://www.lnvh.nl/a-3041/rapport-lnvh:-verborgen-beloningsverschillen -in-de-wetenschap:-vrouwelijke-wetenschappers-do-ask-but-dont-get

LNVH. (2020). Women professors monitor 2020. Dutch Network of Female Professors (LNVH). Retrieved from https://www.lnvh. $\mathrm{nl} /$ monitor2020/EN.html

MacKinnon, D. P., Lockwood, C. M., \& Williams, J. (2004). Confidence limits for the indirect effect: Distribution of the product and resampling methods. Multivariate Behavioral Research, 39(1), 99-128. https://doi.org/10.1207/s15327906mbr3901_4 
McKiernan, E. C., Schimanski, L. A., Muñoz Nieves, C., Matthias, L., Niles, M. T., \& Alperin, J. P. (2019). Use of the Journal Impact Factor in academic review, promotion, and tenure evaluations. PeerJ Preprints 7, e27638v2, https://doi.org/10.7287/ peerj.preprints. $27638 \mathrm{v} 2$

Miller, D. I., Eagly, A. H., \& Linn, M. C. (2015). Women's representation in science predicts national gender-science stereotypes: Evidence from 66 nations. Journal of Educational Psychology, 107(3), 631-644. https://doi.org/10.1037/edu0000005

Miller, D. I., Nolla, K. M., Eagly, A. H., \& Uttal, D. H. (2018). The development of children's gender-science stereotypes: A meta-analysis of 5 decades of U.S. draw-a-scientist studies. Child Development, 89(6), 1943-1955. https://doi.org/10.1111/ cdev.13039

Mitchneck, B., Smith, J. L., \& Latimer, M. (2016). A recipe for change: Creating a more inclusive academy. Science, 352(6282), 148-149. https://doi.org/10.1126/science.aad8493

Morgenroth, T., Ryan, M. K., Rink, F., \& Begeny, C. (2021). The (in) compatibility of identities: Understanding gender differences in work-life conflict through the fit with leaders. British Journal of Social Psychology, 60(2), 448-469. https://doi. org $/ 10.1111 /$ bjso.12411

Moss-Racusin, C. A., Dovidio, J. F., Brescoll, V. L., Graham, M. J., \& Handelsman, J. (2012). Science faculty's subtle gender biases favor male students. Proceedings of the National Academy of Sciences of the United States of America, 109(41), 16474-16479. https://doi.org/10.1073/pnas.1211286109

Naezer, M. M., van den Brink, M. C. L., \& Benschop, Y. W. M. (2019). Harassment in Dutch academia: Exploring manifestations, facilitating factors, effects and solutions. Retrieved from https://repository.ubn.ru.nl/bitstream/handle/2066/20928 2/209282.pdf

National Academy of Sciences. (2021). Sexual harrassment in academic science, engineering and medicine. Retrieved from https://www. nationalacademies.org/our-work/sexual-harassment-in-academia

Nielsen, W., Alegria, S., Börjeson, L., Falk-krzesinski, H. J., Joshi, A., Leahey, E., \& Woolley, A. W. (2017). Gender diversity leads to better science. Proceedings of the National Academy of Sciences of the United States of America, 114(13), E2796. https://doi. org/10.1073/pnas.1703146114

OECD. (2021). Reducing the precarity of academic research careers. OECD Science, Technology and Industry Policy Papers, No. 113, OECD Publishing. https://doi.org/10.1787/0f8bd468-en

Otten, S., \& Epstude, K. (2006). Overlapping mental representations of self, ingroup, and outgroup: Unraveling self-stereotyping and self-anchoring. Personality and Social Psychology Bulletin, 32(7), 957-969. https://doi.org/10.1177/0146167206287254

Peters, K., Ryan, M. K., \& Haslam, S. A. (2013). Women's occupational motivation: the impact of being a woman in a man's world. In Handbook of research on promoting women's careers. Edward Elgar Publishing. https://doi.org/10.4337/9780857938961

Peters, K., Ryan, M. K., \& Haslam, S. A. (2015). Marines, medics, and machismo: Lack of fit with masculine occupational stereotypes discourages men's participation. British Journal of Psychology, 106(4), 635-655. https://doi.org/10.1111/bjop.12106

Peters, K., Ryan, M., Haslam, S. A., \& Fernandes, H. (2012). To belong or not to belong. Journal of Personnel Psychology, 11(3), 148158. https://doi.org/10.1027/1866-5888/a000067

Pronin, E., Steele, C. M., \& Ross, L. (2004). Identity bifurcation in response to stereotype threat: Women and mathematics. Journal of Experimental Social Psychology, 40(2), 152-168. https://doi.org/10.1016/S0022-1031(03)00088-X

San Francisco Declaration of Research Assessment. (2020). Retrieved from https://sfdora.org/read/

Schaufeli, W. B., Salanova, M., González-Romá, V., \& Bakker, A. B. (2002). The measurement of engagement and burnout: A two sample confirmatory factor analytic approach. Journal of Happiness Studies, 3(1), 71-92.

Schmader, T., \& Sedikides, C. (2018). State authenticity as fit to environment: The implications of social identity for fit, authenticity, and self-segregation. Personality and Social Psychology Review, 22(3), 228-259. https://doi.org/10.1177/1088868317 734080

Shen, H. (2013). Inequality quantified: Mind the gender gap. Nature, 495, 22-24. https://doi.org/10.1038/495022a

Shrout, P. E., \& Bolger, N. (2002). Mediation in experimental and nonexperimental studies: New procedures and recommendations. Psychological Methods, 7, 422. https://doi.org/10.1037/1082-989X.7.4.422

Simpson, E. H. (1951). The interpretation of interaction in contingency tables. Journal of the Royal Statistical Society: Series B (Methodological), 13(2), 238-241. https://doi.org/10.1111/j.2517-6161.1951.tb00088.x

Smith, E. R., \& Henry, S. (1996). An in-group becomes part of the self: Response time evidence. Personality and Social Psychology Bulletin, 22(6), 635-642. https://doi.org/10.1177/0146167296226008

Spector, P. E. (2019). Do not cross me: Optimizing the use of cross-sectional designs. Journal of Business and Psychology, 34(2), 125-137. https://doi.org/10.1007/s10869-018-09613-8

Spence, J. T., \& Buckner, C. E. (2000). Instrumental and expressive traits, trait stereotypes, and sexist attitudes what do they signify? Psychology of Women Quarterly, 24(1), 44-62. https://doi.org/10.1111/j.1471-6402.2000.tb01021.x

Storage, D., Charlesworth, T. E., Banaji, M. R., \& Cimpian, A. (2020). Adults and children implicitly associate brilliance with men more than women. Journal of Experimental Social Psychology, 90, 104020. https://doi.org/10.1016/j.jesp.2020.104020

Strategy Evaluation Protocol 2021-2017 VSNU, KNAW, NOW. (2020). Retrieved from https://www.vsnu.nl/files/docum enten/Domeinen/Onderzoek/SEP_2021-2027.pdf

Tajfel, H., \& Turner, J. C. (1979). An integrative theory of intergroup conflict. In S. Worchel \& W. G. Austin (Eds.), The social psychology of intergroup relations (pp. 33-47). Brooks.

Unzueta, M. M., Gutiérrez, A. S., \& Ghavami, N. (2010). How believing in affirmative action quotas affects White women's self-image. Journal of Experimental Social Psychology, 46(1), 120-126. https://doi.org/10.1016/j.jesp.2009.08.017 
Van den Brink, M., \& Benschop, Y. (2012). Gender practices in the construction of academic excellence: Sheep with five legs. Organization, 19(4), 507-524. https://doi.org/10.1177/1350508411414293

Van Veelen, R., Derks, B., \& Endedijk, M. D. (2019). Double trouble: How being outnumbered and negatively stereotyped threatens career outcomes of women in STEM. Frontiers in Psychology, 10, 150. https://doi.org/10.3389/fpsyg.2019.00150

Van Veelen, R., Otten, S., Cadinu, M., \& Hansen, N. (2016). An integrative model of social identification: Self-stereotyping and self-anchoring as two cognitive pathways. Personality and Social Psychology Review, 20(1), 3-26. https://doi.org/10.1177/10888 68315576642

Van Veelen, R., Otten, S., \& Hansen, N. (2013). A personal touch to diversity: Self-anchoring increases minority members' identification in a diverse group. Group Processes and Intergroup Relations, 16(6), 671-683. https://doi.org/10.1177/1368430212 473167

Van Veelen, R., Veldman, J., Van Laar, C., \& Derks, B. (2020). Distancing from a stigmatized social identity: State of the art and future research agenda on self-group distancing. European Journal of Social Psychology, 50(6), 1089-1107. https://doi. org/10.1002/ejsp.2714

Veldman, J., Van Laar, C., Meeussen, L., \& Lo Bue, S. (2021). Daily coping with social identity threat in outgroup-dominated contexts: Self-group distancing among female soldiers. Personality and Social Psychology Bulletin, 47(1), 118-130. https://doi. $\operatorname{org} / 10.1177 / 0146167220921054$

Von Hippel, C., Walsh, A. M., \& Zouroudis, A. (2011). Identity separation in response to stereotype threat. Social Psychological and Personality Science, 2(3), 317-324. https://doi.org/10.1177/1948550610390391

Williams, J. C., \& Dempsey, R. (2014). What works for women at work. New York University Press.

Witteman, H. O., Hendricks, M., Straus, S., \& Tannenbaum, C. (2019). Are gender gaps due to evaluations of the applicant or the science? A natural experiment at a national funding agency. The Lancet, 393(10171), 531-540. https://doi.org/10.1016/ S0140-6736(18)32611-4

Wood, W., \& Eagly, A. H. (2015). Two traditions of research on gender identity. Sex Roles, 73, 461-473. https://doi.org/10.1007/ s11199-015-0480-2

Woolston, C. (2021). Impact factor abandoned by Dutch university in hiring and promotion decisions. Nature, 595, 462. https:// doi.org/10.1038/d41586-021-01759-5

\section{SUPPORTING INFORMATION}

Additional supporting information may be found in the online version of the article at the publisher's website.

Supplementary Material

How to cite this article: Van Veelen, R., \& Derks, B. (2021). Academics as Agentic Superheroes: Female academics' lack of fit with the agentic stereotype of success limits their career advancement. British Journal of Social Psychology, 00, 1-20. https://doi.org/10.1111/bjso.12515 